\title{
Antibodies to T Cells in Patients with Systemic Lupus Erythematosus Can Induce Antibody-dependent
}

\section{Cell-mediated Cytotoxicity against Human T Cells}

\author{
Shunichi Kumagai, Alfred D. Steinberg, and Ira Green, Laboratory of \\ Immunology, National Institute of Allergy and Infectious Diseases, \\ and the Arthritis and Rheumatism Branch, National Institute of \\ Arthritis, Metabolism and Digestive Diseases, National \\ Institutes of Health, Bethesda, Maryland 20205
}

A B S T RACT Patients with active systemic lupus erythematosus (SLE) often have circulating antibodies to $T$ cells. These patients also often have leukopenia and diminished numbers of $T$ lymphocytes. In addition, certain $T$ lymphocyte functions are frequently impaired in patients with SLE. It has been previously considered that a complement-dependent cytotoxic mechanism was responsible for the above observations. We now demonstrate that antibody-dependent cellmediated cytotoxicity (ADCC), a cytotoxic reaction mediated by antibody and effector cells in the absence of complement, can also kill $\mathrm{T}$ cells from normal individuals as well as from patients with SLE. Moreover, this ADCC could be observed using the plasma, effector cells, and target cells all obtained from the same individual with SLE.

Plasma of those patients with active SLE, and in whom anti-T cell antibodies could be demonstrated by the more classical complement-dependent cytotoxicity, was most often able to mediate such an ADCC reaction. The IgG fraction of the plasma was responsible for inducing ADCC, and aggregated IgG could block the reaction. The fact that the IgG fraction was often more effective than the unfractionated plasma suggested that immune complexes present in SLE plasma might partially block the expression of ADCC. Because a single SLE plasma could induce ADCC in $\mathrm{T}$ cells from several different unrelated individuals, it is unlikely that antibodies directed against particular human leukocyte antigens (HLA) or blood group antigens are involved.

Received for publication 12 March 1980 and, in revised form 6 October 1980.

\section{INTRODUCTION}

The sera or plasma from some patients with systemic lupus erythematosus (SLE) ${ }^{1}$ contain antibodies directed against normal leukocytes, especially when the disease is active. These antibodies are thought to be related to the leukopenia observed in many patients with active SLE. Their existence has been demonstrated by a variety of methods such as antiglobulin tests, complementdependent cytotoxicity (CDC) assays (1), and immunofluorescence techniques $(2,3)$. The studies to date have indicated that some of these antibodies are reactive with $T$ lymphocytes and that these antibodies are of the IgG, IgA, and the IgM classes (2-4). Anti-lymphocytic antibodies of the IgM class are especially efficient at mediating complement-dependent lymphocytotoxicity $(5,6)$. In general, IgG antibodies tend to be inefficient in assays employing CDC or immunofluorescence with live cells. However, IgG antibodies can be detected after elution from living cells, by their ability to inhibit mixed lymphocyte reactions (7), or by immunofluorescent techniques using fixed cells $(2,4,8)$.

Recently there has been great interest in the regulation of the immune response, particularly with regard to functional activities of particular $T$ cell subsets (9-15). Some investigators have proposed that anti-T cell antibodies could be responsible for decreased function of suppressor cells (16-18). New Zealand mice with a

\footnotetext{
${ }^{1}$ Abbreviations used in this paper: ADCC, antibodydependent cell-mediated cytotoxicity; CDC, complementdependent cytotoxicity; E/T, effector-to-target cells; HBSS, Hanks' balanced salt solution; SLE, systemic lupus erythematosus; SRBC, sheep erythrocytes.
} 
lupus-like syndrome have antibodies to $\mathrm{T}$ cells and decreased $\mathrm{T}$ cell functions, and have also been reported to have a loss of $\mathrm{T}$ suppressor function (19-21). Sakane et al. (22) showed that IgM anti-lymphocyte antibodies from patients with active SLE, in the presence of complement, preferentially killed suppressor cell precursors; therefore, the loss of suppressor T cells in patients with SLE may (in part, or entirely) be the result of the effects of such antibody activity.

Although much information now exists regarding $\mathrm{T}$ cell damage by antibody and complement in patients with SLE, the role of a mechanism involving antibody in the absence of complement, antibody-dependent cellmediated cytotoxicity (ADCC), has been less carefully explored. In this paper, we have therefore asked whether anti-T cell antibodies in the plasma of patients with SLE were capable of exerting such cytotoxic effects on normal $\mathrm{T}$ cells as well as on their own $\mathrm{T}$ cells. We found that most plasma of patients with active SLE had anti-T cell antibodies, which, in the absence of complement, could mediate $\mathrm{T}$ cell damage in the presence of mononuclear cells.

\section{METHODS}

Plasma of the patients with SLE. All patients met the preliminary criteria proposed by the American Rheumatism Association for the diagnosis of SLE. Clinical activity was assessed at the time of blood drawing by two physicians on the basis of signs and symptoms (active rash, serositis, arthritis, active central nervous system disease, and active renal disease). Patients lacking these symptoms or detectable signs of activity were categorized as inactive. The active patients in this study had at least two of the above criteria of activity.Moreover, all active patients had large quantities of anti-DNA antibodies.

At the time blood was obtained for these studies, patients with active disease had not yet received any treatment. In some instances blood was also drawn from these same patients at a later time when their disease had become inactive. Inactive patients had previously been treated with corticosteroids and occasionally with azathioprine, but were not receiving such treatment at the time of study. In addition, such patients had little detectable anti-DNA antibodies.

All the SLE plasma used had been frozen once and had not been previously thawed. Normal fresh frozen plasma was obtained from healthy adults. All plasma was heated to $56^{\circ} \mathrm{C}$ for $30 \mathrm{~min}$ to inactivate complement and then centrifuged at $105,000 \mathrm{~g}$ for $2 \mathrm{~h}$ at $4^{\circ} \mathrm{C}$ before use to remove aggregated materials.

Effector cells of cell-mediated cytotoxicity and target $T$ cells. Peripheral blood from healthy human donors (obtained from the Blood Bank Department, Clinical Center, National Institutes of Health, Bethesda, Md.) or from patients with SLE was anticoagulated with heparinized saline $(10 \mathrm{U} / \mathrm{ml}$ blood). The blood was then diluted with an equal volume of Hanks' balanced salt solution (HBSS) and $40 \mathrm{ml}$ of the diluted blood was layered over $10 \mathrm{ml}$ of Ficoll-Hypaque solution (FicollHypaque, Pharmacia Fine Chemicals, Div. of Pharmacia Inc., Piscataway, N. J.) and centrifuged at $4^{\circ} \mathrm{C}$ for $30 \mathrm{~min}$ at $400 \mathrm{~g}$. The mononuclear cells were then removed from the interface and washed three times in HBSS. These cells were resuspended in the complete medium, RPMI-1640 (Gibco Laboratories, Grand Island Biological Co., Grand Island, N. Y.) supplemented with $10 \%$ heat-inactivated fetal calf serum (Microbiological Associates, Walkersville, Md). The T cells and non-T cells were prepared as described (23). In brief, neuraminidase-treated sheep erythrocytes (SRBC) and mononuclear cells were mixed in a ratio of 40:1 in HBSS supplemented with $25 \%$ fetal calf serum. This mixture was incubated at $37^{\circ} \mathrm{C}$ for $15 \mathrm{~min}$, spun at $200 \mathrm{~g}$ for $5 \mathrm{~min}$, and incubated on ice for $1 \mathrm{~h}$. The SRBC-lymphocyte suspension was then layered on Ficoll-Hypaque, the SRBC rosettes were pelleted at $400 \mathrm{~g}$ for $20 \mathrm{~min}$ at $4^{\circ} \mathrm{C}$, and the rosetted lymphocytes in the pellet fraction were removed and further purified by rerosette formation, which was accomplished by the addition of a second portion of neuraminidase-treated SRBC, and subsequent centrifugation. The rosetted lymphocytes in the pellet from the final Ficoll-Hypaque gradient were suspended in $0.83 \%$ ice-cold ammonium chloride- $0.17 \mathrm{M}$ Tris buffer, $\mathrm{pH}$ 7.2 , to remove SRBC by hypotonic lysis, centrifuged, washed twice in HBSS, and then resuspended in the complete culture medium. We will refer to this preparation as $\mathrm{T}$ lymphocytes. The $\mathrm{T}$ cell fraction contained $>98 \%$ rosette-positive cells and $<1 \% \mathrm{Ig}^{+}$cells. The interface cells, obtained after the second cycle of the $T$ cell purification procedure used above, were designated non- $T$ cells. These contained less than $1 \% \mathrm{E}$ rosetting cells, $50-60 \%$ surface immunoglobulinpositive cells, and $20-30 \%$ monocytes as judged by Giemsa staining. These non-T cells were then further separated into adherent and nonadherent populations by overnight incubation on plastic petri dishes at $37^{\circ} \mathrm{C}$. The adherent cells were then obtained by removal with a rubber policeman. These adherent cells consisted of $95 \%$ monocytes as judged by Giemsa staining; $70 \%$ of the nonadherent cells stained for surface immunoglobulin.

T cells were used as the target cells for ADCC; unfractionated lymphocytes, $T$ cells, and non-T cells (unseparated, adherent, and nonadherent) were all tested for their ability to act as effector cells for ADCC. The unfractionated lymphocytes gave the greatest ADCC (Fig. 1) and were therefore used as effector cells for the rest of the experiments described in this paper.

Preparation of IgG and IgM fractions of plasma by Sephadex G-200 column chromatography. Plasma was precipitated with $50 \%$ ammonium sulfate, dialyzed against buffer, and applied to a 1.5-m long Sephadex G-200 (Pharmacia Fine Chemicals Inc.) column. Individual fractions were collected, and the optical density at $280 \mathrm{~nm}$ of each fraction measured in a

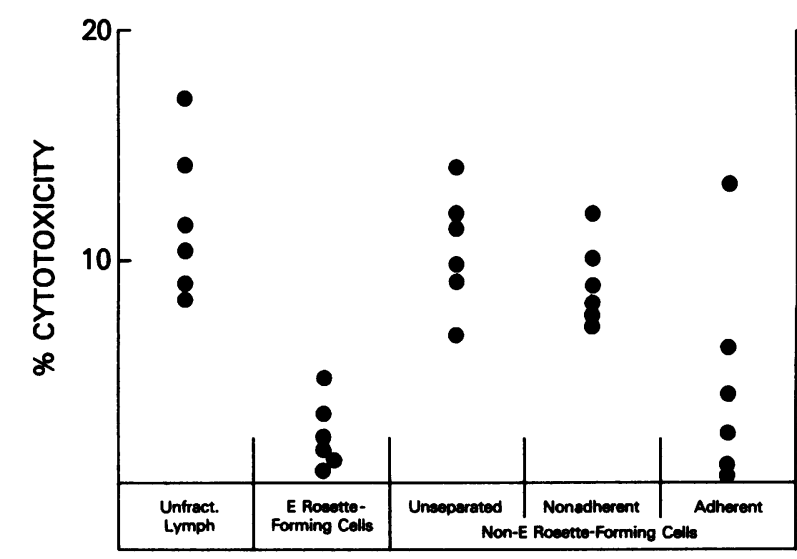

FIGURE 1 Various lymphocyte populations were tested for their ability to mediate ADCC. T cells treated with plasma from patients with active SLE were used as the target cells. The E/T ratio used was 25:1. 
spectrophotometer. Marker proteins were run to confirm the approximate size of molecules obtained from the resulting peaks. A good separation of IgM and IgG peaks was observed. The purity of each fraction was confirmed by radial immunodiffusion of 20-fold concentrated samples using specific antibodies to human IgG or human IgM. To check further their purity, the peaks were separately rechromatographed; no IgG was found in the IgM fraction, and no IgM was found in the IgG fraction. Thus, no IgM-IgG or IgG-IgG complexes were present in the IgM fraction because IgG was not detectable in this fraction. The IgM and IgG peaks were separately pooled and concentrated. Individual fractions were dialyzed over-

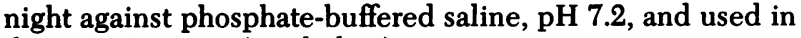
the ADCC assays (see below).

Detection of anti-T cell antibodies by CDC using the dye exclusion test. $10^{7} \mathrm{~T}$ cells were suspended in $1 \mathrm{ml}$ of the medium supplemented with $40 \%$ SLE plasma, fractionated plasma, or normal plasma and left at $4^{\circ} \mathrm{C}$ overnight. $200 \mathrm{ml}$ of fresh AB serum was then added as a complement source, and the cells were cultured an additional $2 \mathrm{~h}$ at $25^{\circ} \mathrm{C}$. The total number of cells and the percentage of viable cells (dye exclusion) were then determined using trypan blue at a final concentration of $0.05 \%$.

$\%$ cell killing

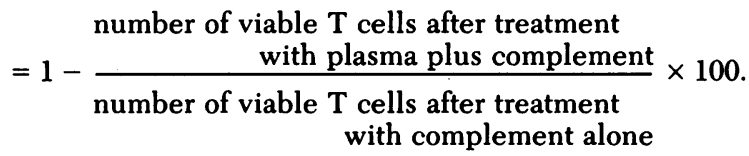

ADCC assay. ADCC was performed by a modification of previously published methods (24-26). $10 \times 10^{6}$ purified target $T$ cells obtained from normal donors or patients with SLE were cultured at $4^{\circ} \mathrm{C}$ overnight in the presence of $40 \%$ normal plasma or SLE plasma. Effector and target T cells were always from the same donor except for some of the experiments shown in Fig. 8. Plasma was either from the same donor as the cell donor or from other individuals. In some cases the target of cells were incubated as above with the IgG or IgM fraction of plasma. Here, the IgG and IgM fractions were diluted to be equivalent to the concentrations of IgG and IgM that would be present in $40 \%$ plasma. In the studies in which the IgG and IgM fractions were used to treat the target $\mathrm{T}$ cells, $10 \%$ heat-inactivated fetal calf serum was also added to the overnight cultures.

The plasma or IgG or IgM-treated T cells were washed one time and then incubated at $37^{\circ} \mathrm{C}$ for $1 \mathrm{~h}$ with $100 \mu \mathrm{Ci} / 0.1 \mathrm{ml}$ [ ${ }^{51} \mathrm{Cr}$ ]sodium chromate (New England Nuclear, Boston, Mass.) and washed three times with HBSS. In some instance, the IgG-treated target cells were not radiolabeled and were used in cold target inhibition studies (Results). Autologous unfractionated mononuclear effector cells, $2.5 \times 10^{5}$, were mixed with $1 \times 10^{4}$ of the above ${ }^{51} \mathrm{Cr}$-labeled $\mathrm{T}$ cells in wells of a Falcon V-bottom plate in a total volume of $200 \mu \mathrm{l}$ in RPMI1640 supplemented with $10 \%$ heat-inactivated fetal calf serum. The plate was incubated for $6 \mathrm{~h}$ at $37^{\circ} \mathrm{C}$ in a humidified atmosphere containing $5 \% \mathrm{CO}_{2}$. Although the effector-totarget cell $(\mathrm{E} / \mathrm{T})$ ratio usually used was $25: 1$, in some experiments this ratio was varied. This method is called the "preculture method."

In some experiments the $\mathrm{T}$ cells were first ${ }^{51} \mathrm{Cr}$-labeled, and then the SLE or normal plasma was added together with the effector cells; the plasma was present continuously (at a concentration of $20 \%$ ) during the 6 -h cytotoxic assay. This is called the "co-culture method."

The percent cytotoxicity was calculated as follows: at the end of the incubation period, the plates were centrifuged at
$300 \mathrm{~g}$ for $10 \mathrm{~min}$, a $100-\mu \mathrm{l}$ portion of the supernate was removed from each well, and its radioactivity was counted in a gamma spectrometer. Maximum possible ${ }^{51} \mathrm{Cr}$ release was determined by three freeze-thaw cycles. The spontaneous release from wells without effector cells was also determined:

$$
\begin{aligned}
& \text { counts per minute test sample } \\
& \% \text { cytotoxicity }=\frac{- \text { spontaneous release }}{\text { maximum release }} \times 100 \text {. } \\
& \text { - spontaneous release }
\end{aligned}
$$

All experiments were done in triplicate. Statistical analysis was performed with Student's $t$ test.

Detection of anti-T cell antibodies by $C D C$ using ${ }^{51} \mathrm{Cr}$ release. To determine the magnitude of CDC on these same populations of plasma-treated T cells, portions of these same ${ }^{51} \mathrm{Cr}$-labeled T cells in microtiter plates were cultured for $6 \mathrm{~h}$ at $37^{\circ} \mathrm{C}$ with $100 \mu \mathrm{l}$ of $33 \%$ fresh normal $\mathrm{AB}$ sera (as complement source) instead of the effector cells. It should be noted that here the T cells were first incubated with the SLE plasma and then washed exactly as in the preculture method for the ADCC (see above). The percent cytotoxicity was calculated using the same formula that was used to calculate the percent cytotoxicity for ADCC.

Preparation of aggregated human IgG and its inhibition of ADCC. Cohn Fraction II of human IgG (Miles Laboratories, Inc., Elkhart, Ind.) was dissolved in phosphate-buffered saline at the concentration of $20 \mathrm{mg} / \mathrm{ml}$ and heated at $63^{\circ} \mathrm{C}$ for $15 \mathrm{~min}$. The aggregates were homogenized in phosphatebuffered saline and centrifuged at $1,000 \mathrm{~g}$ for $30 \mathrm{~min}$. The supernate was collected, and the protein concentration was measured by optical density $(280 \mathrm{~nm})$ using a spectrophotometer. These finer aggregates of IgG were then diluted in complete culture medium. The effector cells were either untreated or treated with various concentrations of the aggregates for $30 \mathrm{~min}$ and not washed. They were then added to the preculture ADCC assay as described above, and the percent cytotoxicity was measured.

\section{RESULTS}

Comparison of preculture and co-culture ADCC methods. We compared two methods of ADCC using highly purified $\mathrm{T}$ cells from normal individuals as targets and their own unfractionated lymphocytes as effector cells. In the preculture method the plasma from four patients with active SLE showed $17.1 \pm 2 \%$ (mean $\pm \mathrm{SE}$ ) cytotoxicity at a $25: 1 \mathrm{E} / \mathrm{T}$ ratio (Fig. 2 ). In contrast, if the target cells were labeled with ${ }^{\left[{ }^{51} \mathrm{Cr}\right] \text { sodium }}$ chromate first and then incubated with the same SLE plasma and effector cells (co-culture), only $3.6 \pm 0.9 \%$ $($ mean $\pm \mathrm{SE})$ cytotoxicity was observed $(P<0.01$ vs. preculture method). These results demonstrated that when SLE plasma was continuously present during the entire culture period ADCC was inhibited.

To analyze why this result was observed, we incubated unfractionated effector cells overnight at $4^{\circ} \mathrm{C}$ with a concentration of purified IgG equal to that which would be present in $40 \%$ plasma (see above). These cells were then washed three times and used in the ADCC assay at various E/T ratios. As shown in Fig. 3, such treatment of the effector cells markedly diminished their capacity to mediate ADCC. One explanation for 


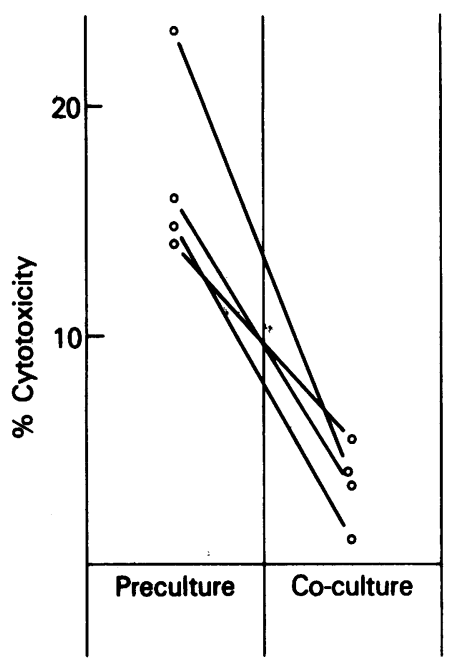

Figure 2 Comparison of the preculture method with the coculture method for ADCC. In the preculture method, the target $T$ cells were incubated with plasma and then washed beffore incubation with the effector cells. In the co-culture method the same target cells and effector cells were cultured in the continuous presence of the same plasma.

this result is that "cold" $T$ cells in the effector population become coated with anti-T cell antibodies and inhibit by a cold target mechanism. To determine directly whether this was the case, the following experiment was performed. Here various numbers of $T$ cells, preincubated with IgG fraction of SLE plasma but which were not radiolabeled, were added to the standard ADCC system. T cells not treated with the IgG fraction of SLE plasma were used as a control. As shown in Fig. 4 the addition of IgG-treated cold T cells markedly inhibited the ADCC. For this reason all further experiments were performed using the preculture method in
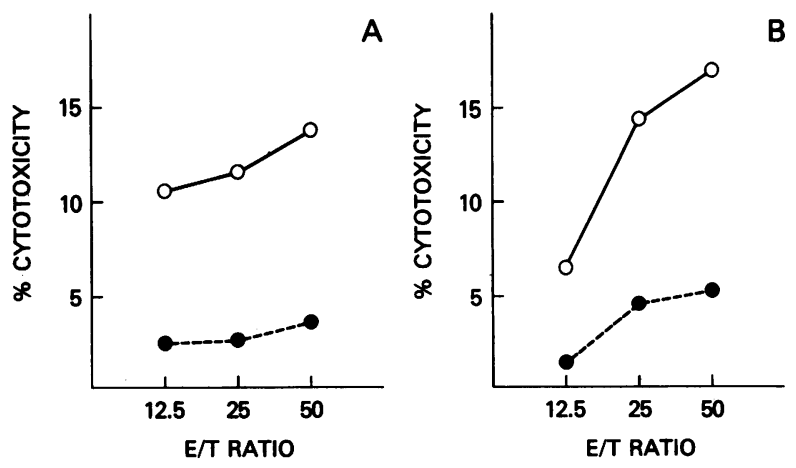

Figure 3 The results of pretreating the effector cell population with the IgG fraction of SLE plasma on the ADCC reaction. (A) Target $\mathrm{T}$ cells were coated with plasma from a patient with active SLE. (B) Target T cells were coated with the IgG fraction of this same plasma. $O$, untreated effector cells; 9 , IgG-treated effector cells.
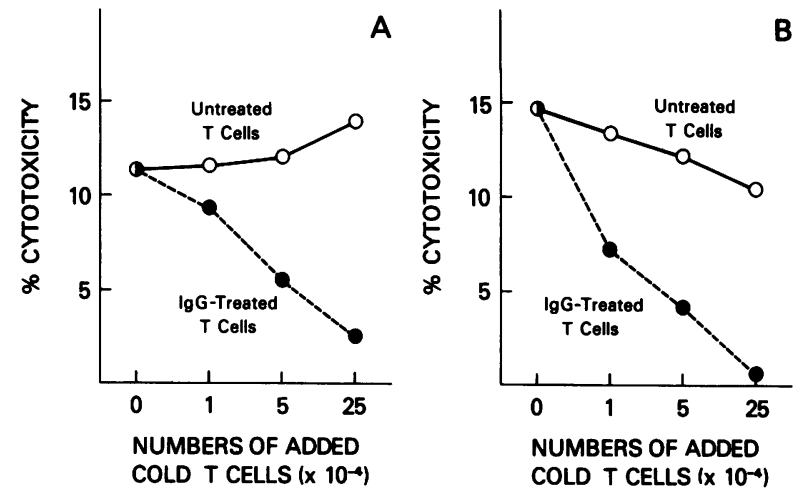

Figure 4 Nonradiolabeled $\mathrm{T}$ cells were either treated (O) or not treated (O) with the IgG fraction of SLE plasma. Those $\mathrm{T}$ cells were then added to the standard ADCC assay to determine whether they could cause cold target inhibition. The number of radiolabeled target $T$ cells used was $1 \times 10^{4}$ and the number of effector cells used was $25 \times 10^{4}$. Panels A and $B$ show the result of two separate experiments.

which the T cells were first treated with SLE plasma and then washed.

Comparison of ADCC and CDC using SLE plasma. 14 normal plasma, 8 plasma from inactive SLE patients, and 9 plasma from active SLE patients were tested for ADCC activity. The percent cytotoxicity (mean $\pm \mathrm{SE}$ ) for these three groups was $1.4 \pm 0.4,2.6 \pm 0.5$, and $11.6 \pm 2.0$, respectively. The active SLE group was significantly different from the other two groups, $P<0.01$. The upper limit (the mean $\pm 2 \mathrm{SD}$ ) of normal subjects, $4.4 \%$, was used as the upper limit of normal. By this criterion, eight of nine active SLE plasma showed significant ADCC (Fig. 5A). In contrast, all eight inactive SLE plasma tested for ADCC activity produced cytotoxicity levels that were within normal limits. These results demonstrate that normal $\mathrm{T}$ lymphocytes can be destroyed by autologous unfractionated mononuclear cells in the absence of complement when these T cells are pretreated with the plasma of active SLE patients.

The same labeled target $\mathrm{T}$ cells used as targets for ADCC were also used for the simultaneous measurement of CDC $\left({ }^{51} \mathrm{Cr}\right.$ release technique) using some of the above plasma (individually numbered 1-7). The normal and inactive SLE plasma showed no cytotoxicity. However, plasma from the five patients with active SLE studied showed a CDC of $11.2 \pm 0.8 \%$ cytotoxicity $(P<0.01$ compared with the other two groups) (Fig. 5B). When CDC induced by seven of these plasma was measured by dye exclusion techniques, all the plasmas from active patients caused significant cytotoxicity, whereas only one plasma from an inactive SLE patient showed cytotoxicity (Fig. 5C). Thus, those sera numbered 1-6 that demonstrated anti- $\mathrm{T}$ cell antibodies by the classical technique (dye exclusion) were the same that were 


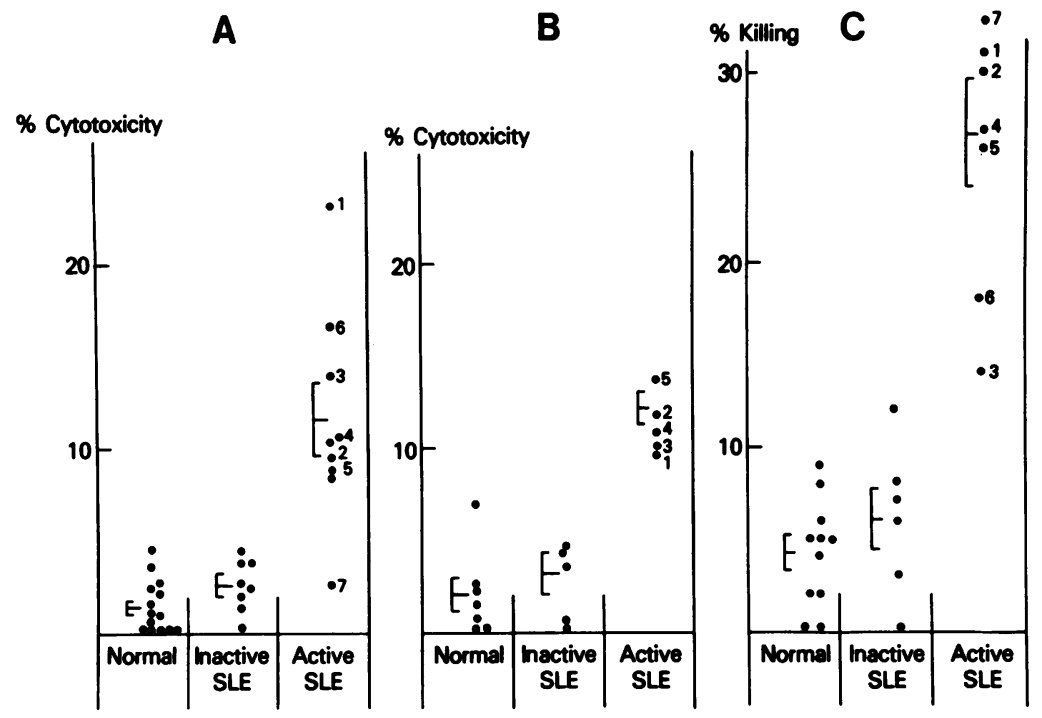

FIGURE 5 Using purified T cells as targets, the percent cytotoxicity on purified $\mathrm{T}$ cells by either ADCC (A), or complement-mediated cytotoxicity by ${ }^{51} \mathrm{Cr}$ release (B), or complement-mediated cytotoxicity by dye exclusion test $(C)$ is shown. The individually numbered values show the effects of the same plasma in the three different assays. Vertical bars show the mean $\pm \mathrm{SE}$.

able to mediate ADCC. However, their rank order of efficiency in the different assays varied somewhat. It should also be noted that plasma 7 , which was able to mediate CDC by dye exclusion (Fig. 5C), was unable to mediate ADCC (Fig. 5A). The dye exclusion technique may give a somewhat greater degree of cytotoxicity than the ${ }^{51} \mathrm{Cr}$ release technique because the procedure of ${ }^{51} \mathrm{Cr}$ labeling and washing of $\mathrm{T}$ cells that had been treated with SLE plasma may have killed

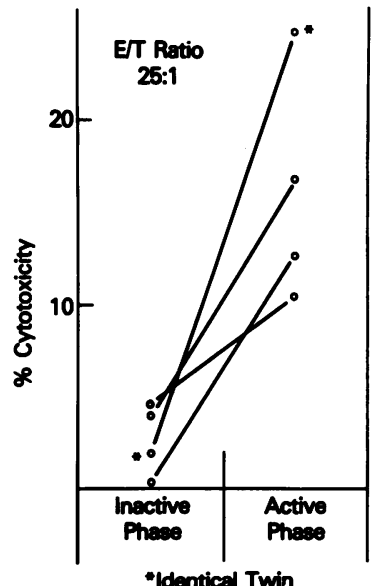

FIGURE 6 The percent cytotoxicity by ADCC using three plasmas from patients obtained during the inactive phase of disease and during the active phase of disease. The starred values $\left({ }^{*}\right)$ from plasma obtained simultaneously from a set of identical twins, one of whom was active and one of whom was inactive. some of the more sensitive cells; therefore, they may not be present during the actual $6-\mathrm{h}^{51} \mathrm{Cr}$ release assay.

Comparison of ADCC mediated by active plasma and inactive plasma from the same patient with SLE. ADCC activity of three pairs of plasma from patients with active SLE was compared with the ADCC activity using plasma from the same patients when they were inactive (Fig. 6). A fourth pair of plasma came from identical twins discordant with regard to disease activity. These results revealed that plasma of SLE patients supported significant ADCC activity when obtained in the active phase but not in the inactive phase of disease.

Reproducibility of ADCC with different $T$ cell donors. Three active SLE plasma were studied for their ADCC activity against T lymphocytes from three unrelated normal subjects. As shown in Table I, these

TABLE I

Reproducibility of ADCC using Different Lymphocytes as Targets

\begin{tabular}{|c|c|c|c|c|}
\hline \multirow[b]{2}{*}{ SLE plasma } & \multicolumn{3}{|c|}{ Blood donors (normal) } & \multirow[b]{2}{*}{ Mean \pm SE } \\
\hline & A & B & C & \\
\hline $3 *$ & $12.8 \neq$ & 14.0 & 9.7 & $12.2 \pm 1.3$ \\
\hline 4 & 8.8 & 16.0 & 10.8 & $11.9 \pm 2.1$ \\
\hline 6 & 16.8 & 14.4 & ND & $15.6 \pm 1.2$ \\
\hline
\end{tabular}

* Patient numbers correspond with the ones shown in Fig. 5. \$ Values are percent cytotoxicity. ND, not done. No normal plasma showed more than $4.3 \%$ of cytotoxicity against any target cells. 
three plasma mediated significantly higher ADCC against all three normal target cells than did plasma from normal subjects. These results suggest that active SLE plasma act on T cells from any subjects and are not restricted to $T$ cells bearing any particular human leukocyte antigen (HLA) type.

Specificity and antibody nature of the factor in the SLE plasma leading to cell-mediated lysis. IgG has been implicated as the major antibody class involved in ADCC, though several investigators reported that IgM antibody could also induce ADCC $(27,28)$. To determine whether the effective fraction of SLE plasma that mediated ADCC was an antibody of the IgG or IgM class, the IgG and IgM fractions of three patients with SLE and one normal individual were obtained by gel filtration and used for ADCC. First, the plasma and plasma fractions were tested for anti- $T$ cell antibody by dye exclusion (Table II). Patient I was active and had anti-T cell antibodies of the IgM class as measured by CDC. Patient II was mildly active, and patient III had inactive SLE. No antibodies were present in the plasma of these latter two patients or the normal individual by this method of CDC.

Fig. 7 shows the results of ADCC using unfractionated and fractionated plasma from these three patients. In patient I, higher ADCC activity was found in the IgG fraction than in unfractionated plasma; the IgM fraction showed minimal ADCC activity despite containing most of the antibody active in CDC. In patients II and III, ADCC activity was shown only with the IgG fraction, and not in unfractionated plasma. Neither the IgG nor the IgM fraction from plasma from a normal individual could mediate ADCC. These results suggest that IgG was the major antibody class effective in our cell-mediated assay of ADCC.

The use of effector cells and target cells from patients with SLE. To help establish the relevance of an ADCC mechanism to the lymphopenia and immune

\section{TABLE II}

$C D C$ with the $\operatorname{IgG}$ and IgM Fraction of SLE Plasma (Dye Exclusion Test)

\begin{tabular}{lcrc}
\hline \multicolumn{1}{c}{ Patients } & $\begin{array}{c}\text { Unfractionated } \\
\text { plasma }\end{array}$ & $\begin{array}{c}\text { IgG } \\
\text { fraction }\end{array}$ & $\begin{array}{c}\text { IgM } \\
\text { fraction }\end{array}$ \\
\hline I* (active) & & $\%$ killing & \\
II (mildly active) & $\frac{27 \ddagger}{7}$ & 7 & $\frac{34}{9}$ \\
III (inactive) & 8 & 11 & 0 \\
Normal & 2 & 5 & 0 \\
\hline
\end{tabular}

* Patient numbers correspond with the ones shown in Fig. 7. $\$$ Values are percent killing. The means of the underlined values are significantly greater than the percent killing observed with normal plasma $(4.4 \pm 1 \%)$.
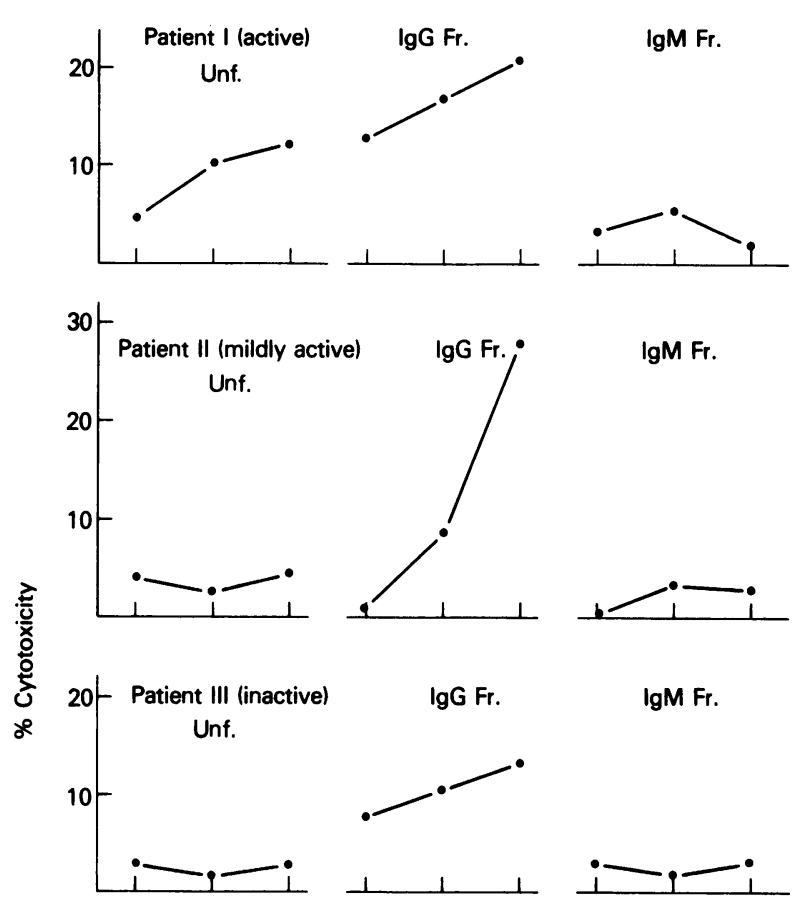

$\lg \mathrm{M} \mathrm{Fr}$.

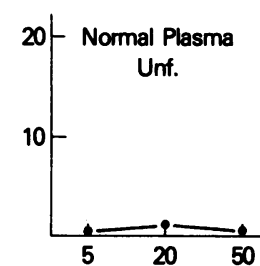

lg G Fr.
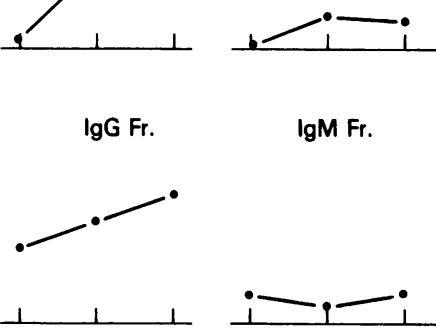

$\lg \mathrm{M} \mathrm{Fr}$.

$\lg \mathrm{Fr}$.

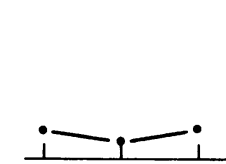

$\operatorname{lgM} \mathrm{Fr}$.
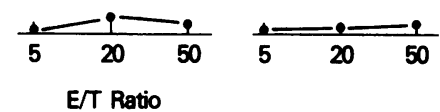

FIGURE 7 The percent cytotoxicity by ADCC of unfractionated plasma from SLE patients and a normal individual and the IgG and IgM fractions of these plasma.

dysfunction in vivo patients with SLE, we thought it important to demonstrate that cells from SLE patients could also mediate this effect. In Fig. 8 we show that effector cells from patients with SLE could mediate ADCC against their own target $\mathrm{T}$ cells. A dosedependent increase in cytotoxicity, characteristic of ADCC, was also observed. Moreover, in this experiment only plasma from patients with active SLE resulted in maximal ADCC.

Inhibition of lymphocyte-mediated cytotoxicity with aggregated IgG. Immune complexes and aggregated IgG are known to suppress the ADCC reaction $(29,30)$. To determine whether our cell-mediated cytotoxicity was also inhibited by aggregated IgG, several concentrations of aggregated IgG were added to our system. As shown in Fig. 9, ADCC activities observed in two active SLE plasma were inhibited in a dose-response fashion by aggregated IgG. 

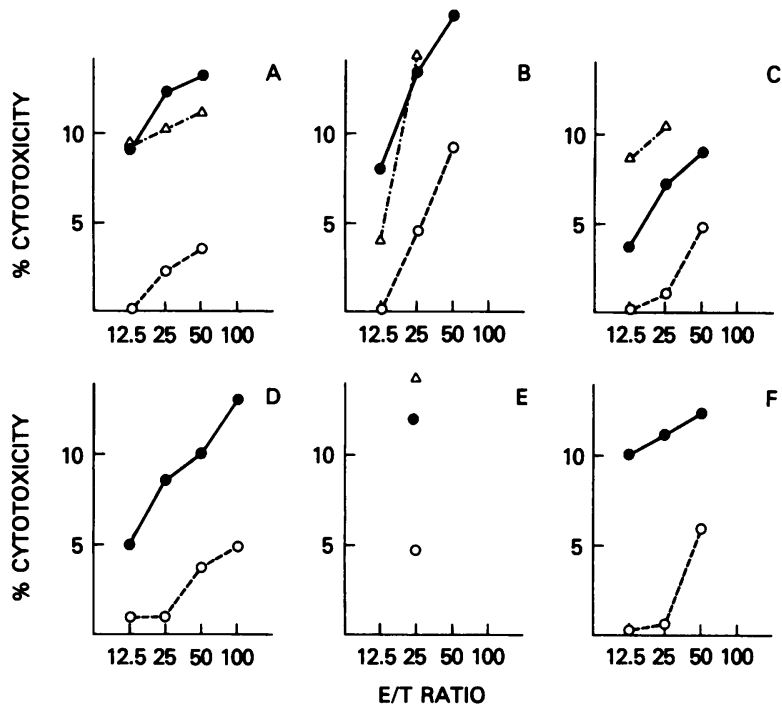

FIGURE 8 The ability of effector cells and plasma from patients with SLE to mediate ADCC against their own T cells. In all cases, the target $T$ cells come from patients with inactive SLE. (O) Plasma from patients with active SLE, effector cells from patients with inactive SLE. (O) Plasma from patients with inactive SLE, effector cells from patients with inactive SLE. $(\triangle)$ Plasma from patients with active SLE, effector cells from normal individuals. In each case, the active and inactive plasmas used are syngeneic with the target cell. Each panel is the result of a separate individual. Shown are the percent cytotoxicity at different $\mathrm{E} / \mathrm{T}$ ratios.

\section{DISCUSSION}

It is known that patients with active SLE show markedly reduced numbers of peripheral blood lymphocytes, especially during the active phases of their disease.

INHIBITION OF ADCC WITH AGGREGATED IgG

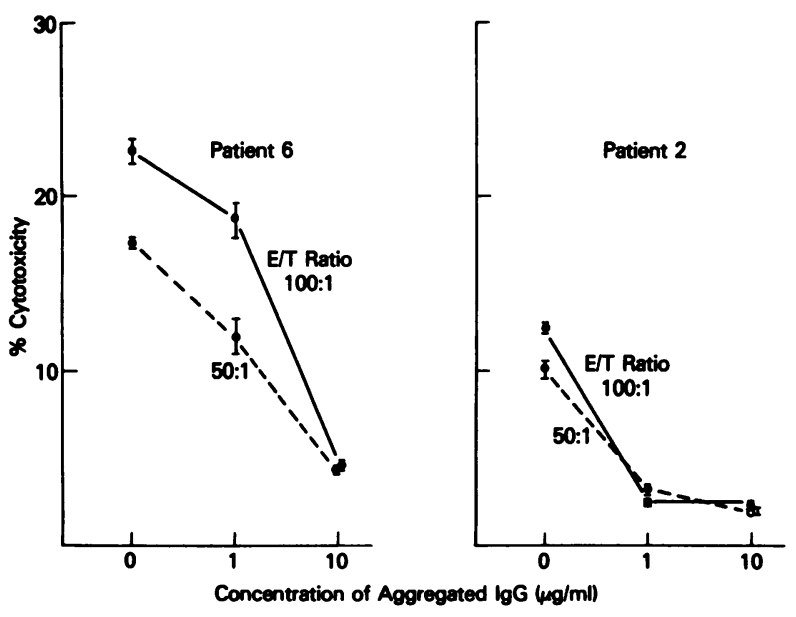

FIGURE 9 Inhibition of ADCC by various concentrations of aggregated IgG. Patient numbers correspond with the plasmas of patients used for the experiments shown in Fig. 5 .
Although the reduction includes both $B$ and $T$ cells (4, 31,32 ), B cell function remains hyperactive, whereas there is often an impairment of certain $T$ cell functions. These $T$ cell defects are most prominent in patients with active disease, and are minimal in patients with inactive disease (4). Moreover, it has been suggested that the excessive B cell activity may stem (at least in part) from reduced $T$ cell suppressor function; a role for anti- $T$ cell antibody in the $T$ suppressor defect has been postulated (16-18).

Because autoantibodies to $T$ cells were found in patients with SLE (2-6) as well as in New Zealand mice with a lupus-like syndrome (19-21), their participation in the reduction of $T$ cell numbers and the impairment of $\mathrm{T}$ cell functions have been actively investigated $(7,14-18,33,34)$. The proposed mechanism for both of these effects has most often been considered to be complement-mediated cytotoxicity. Antibodies of the IgM class are thought to be principally involved in this cytotoxicity, and are capable of eliminating suppressor T cell function (14-18). However, IgG antibodies also occur in patients with SLE; these antibodies have been also reported to be able to impair certain lymphocyte functions, such as the mixed lymphocyte reaction and $\operatorname{ADCC}(7,33,34)$.

In this report we now demonstrate that $\mathrm{T}$ cell damage by plasma of patients with active SLE may also be mediated by a complement-independent mechanism, namely ADCC. ADCC was observed using both normal and SLE lymphocytes as target and effector cells. Furthermore, this ADCC was observed using the plasma, effector cells, and target cells from the same individual with SLE. Such an observation strongly suggests that such an ADCC mechanism may be one of the explanations for the lymphopenia and immune dysfunctions observed in patients with SLE. Thus, our results are similar to previous studies of various diseases or disease models in which specific naturally occurring antibodies injured target cells bearing specific antigen by cooperation with mononuclear cells (35-39). These examples include antibodies to tumor cells (35), erythrocytes (36), and viruses (37-39).

Moreover, anti-DNA antibodies in the serum of patients with SLE have been shown to act as specific antibodies using a model target cell, cell-mediated lysis of DNA-coated cells $(40,41)$. In addition, Glinski et al. (42) observed a reduction in a subpopulation of $T$ cells in patients with SLE; an IgG fraction of SLE sera could also induce, in vitro, a reduction of this same fraction in normal lymphocyte populations. Because the reaction was inhibited by heat-aggregated human gamma globulin, they speculated that ADCC might have been the mechanism involved (42).

This speculation is now confirmed by our results. Indeed, the IgG fraction of sera from patients with 
SLE, but not from a normal individual, were demonstrated to be capable of killing purified normal T lymphocytes by an ADCC mechanism. An additional point is that the specificity of this reaction and the role of IgG are shown by the fact that it could be blocked by cold $\mathrm{T}$ cells coated with the IgG fraction from SLE plasma (Fig. 4). It is also unlikely that this activity of plasma from patients with SLE is a result of the presence of specific isohemagglutins, or anti-HLA antibodies, because a single plasma could induce ADCC in populations of lymphocytes from several different unrelated individuals. Anti-T cell antibodies themselves, in the plasma of patients with SLE, are most likely to be the effector antibodies in the ADCC we have observed.

Although there have been some reports that antibodies of the IgM class are capable of mediating ADCC $(27,28)$, we observed that only the IgG fractions of plasma of patients with SLE were able to exert significant ADCC (Fig. 7). This is consistent with the finding of Longmire et al. (43), who found that an IgG fraction from supernates of cultured spleen lymphocytes from patients with Hodgkin's disease could also mediate ADCC against autologous T lymphocytes. We assume that most patients with active SLE have both IgM and IgG anti-T cell antibodies. However, plasma from patient 7 in Fig. 5 demonstrated a high level of CDC and no ADCC activity. In this patient it is possible that only anti-T cell antibodies of the IgM class were present.

In the course of our studies we observed cases in which unfractionated plasma from patients with SLE could not mediate ADCC but in which the IgG fraction could. The presence of inhibiting immune complexes in the unfractionated plasma might explain these observations. The possibility is supported by the finding that aggregated IgG could inhibit ADCC by whole plasma. In addition, our observation that the ADCC assay performed in the continuous presence of SLE plasma (co-culture method) failed to show high levels of ADCC, whereas preincubation of the target cells with plasma followed by washing (preculture method) produced higher levels of ADCC, might also be explained by the presence of immune complexes in some of these plasma. In this regard, several other investigators have noted that SLE sera also suppressed ADCC activity of normal human peripheral blood mononuclear cells against Chang cells or chicken erythrocytes $(34,44-$ 47). Another reason for the failure of the co-culture method is that unlabeled $T$ cells present in the effector cell population could have interacted with the anti-T cell antibody in the SLE plasma; here "cold target inhibition" could have occurred, and, thus, could have reduced the degree of ADCC observed. Indeed the results of the experiments shown in Figs. 3 and 4 support these ideas. In addition, antibodies to the effector cells of
ADCC may have also inhibited the reaction when plasma was co-cultured throughout the ADCC reaction.

Of interest was the fact that the IgG fraction of the plasma of patients II and III (Table II and Fig. 7) with inactive disease could mediate ADCC in the absence of demonstrable complement-mediated cytotoxicity. Thus, ADCC activity may be a very sensitive method to detect anti-T cell antibodies in patients with inactive disease and with low levels of anti-T cell antibodies.

We have not yet studied functional impairments that might be produced by a cytotoxic ADCC mechanism. However, a previous study has suggested that a subpopulation of $T$ cells may be removed selectively by the ADCC mechanism (42). Moreover, Twomey et al. (16), using unfractionated plasma, and Sagawa and Abdou (18), using the IgG fraction of SLE sera, could, in the absence of complement, inhibit the development of concanavalin A-induced suppressor function. These observations could be explained by such an ADCC mechanism selectively eliminating suppressor $\mathrm{T}$ cells. Finally, whereas complement-dependent lymphocytotoxicity mediated by IgM is optimally observed at temperatures from $4^{\circ}$ to $15^{\circ} \mathrm{C}(14), \mathrm{ADCC}$ appears to work effectively at higher temperatures. Thus, it is possible that at body temperature ADCC may be an important mechanism by which regulatory $T$ cell subsets are deleted in patients with SLE.

\section{ACKNOWLEDGMENTS}

The authors are grateful to Doctors Paul V. Holland, Richard Davey, and Harvey Klein, and Ms. Jane E. Kendall, Blood Bank Department, Clinical Center, National Institutes of Health, for their help and cooperation in supplying the blood from normal humans in these studies. We also wish to thank Mr. Charles Hoes for his excellent technical assistance, and Mr. J. Patton Reeves for separating the SLE plasma into IgG and IgM fractions.

\section{REFERENCES}

1. Terasaki, P. I., V. D. Mottironi, and E. V. Barnett. 1970. Cytotoxin in disease. N. Engl. J. Med. 238: 724-728.

2. Messner, R. P., M. S. Kennedy, and J. G. Jelinek. 1975. Antilymphocyte antibodies in systemic lupus erythematosus. Effect on lymphocyte surface characteristics. Arthritis Rheum. 18: 201-206.

3. Steinberg, A. D., L.W. Klassen, D. R. Budman, and G. W. Williams. 1979. Immunofluorescence studies of anti-T cell antibodies and $\mathrm{T}$ cells in systemic lupus erythematosus. Selective loss of brightly staining $T$ cells in active disease. Arthritis Rheum. 22: 114-122.

4. Raveche, E. S., and A. D. Steinberg. 1979. Lymphocytes and lymphocyte function in SLE. Clin. Haematol. 16: 344-370.

5. Stastney, P., and M. Ziff. 1971. Antibodies against cell membrane constituents in systemic lupus erythematosus and related diseases. I. Cytotoxic effect of serum from patients with systemic lupus erythematosus (SLE) for allogeneic and for autologous lymphocytes. Clin. Exp. Immunol. 8: 543-550. 
6. Winfield, J. B., R. J. Winchester, P. Wernet, S. M. Fu, L. Masaitis, and V. E. Pollak. 1974. Lymphocytotoxic antibodies to lymphocyte surface determinants in systemic lupus erythematosus. Arthritis Rheum. 18: 1-8.

7. William, R. C., Jr., R. B. Lies, and R. P. Messner. 1973. Inhibition of mixed leucocyte culture responses by serum and globulin fractions from certain patients with connective tissue disorders. Arthritis Rheum. 16: 597-605.

8. Husby, G., and R. P. Messner. 1977. Detection of antilymphocyte antibodies in patients with systemic lupus erythematosus by indirect immunofluorescence on acetone-fixed lymphocytes. J. Lab. Clin. Med. 89(2): 240-249.

9. Abdou, N. I., A. Sagawa, E. Pascual, J. Habert, and S. Sadeghee. 1976. Suppressor T-cell abnormality in idiopathic systemic lupus erythematosus. Clin. Immunol. Immunopathol. 6: 192-199.

10. Bresnihan, B., and H. E. Jasin. 1977. Suppressor function of peripheral blood mononuclear cells in normal individuals and in patients with systemic lupus erythematosus J. Clin. Invest. 59: 106-116.

11. Morimoto, C. 1978. Loss of suppressor T-lymphocyte function in patients with systemic lupus erythematosus (SLE). Clin Exp. Immunol. 32: 125-133.

12. Fauci, A. S., A. D. Steinberg, B. F. Haynes, and G. Whalen. 1978. Immunoregulatory aberrations in systemic lupus erythematosus. J. Immunol. 121: 1473-1479.

13 Sagawa, A., and N. T. Adou. 1978. Suppressor cell dysfunction in systemic lupus erythematosus. J. Clin. Invest. 62: 789-796.

14. Sakane, T., A. D. Steinberg, and I. Green. 1978. Studies of immune functions of patients with systemic lupus erythematosus. I. Dysfunction of suppressor T-cell activity related to impaired generation of rather than response to suppressor cells. Arthritis Rheum. 21: 657-664.

15. Strelkauskas, A. J., R. T. Callery, Y. Borel, and S. F. Schlossman. 1979. Functional characteristics of human Tlymphocyte subsets identified by sera from patients with systemic lupus erythematosus. Clin. Immunol. Immunopathol. 14: 47-55.

16. Twomey, J. J., A. H. Laughter, and A. D. Steinberg. 1978. A serum inhibitor of immune regulation in patients with systemic lupus erythematosus. J. Clin. Invest. 62: 713-715.

17. Sakane, T., A. D. Steinberg, and I. Green. 1979. Studies of immune functions of patients with systemic lupus erythematosus; complement-dependent immunoglobulin $\mathbf{M}$ anti-thymus-derived cell antibodies preferentially inactivate suppressor cells. J. Clin. Invest. 63: 954-965.

18. Sagawa, A., and N. I. Abdou. 1979. Suppressor-cell antibody in systemic lupus erythematosus: possible mechanism for suppressor cell dysfunction. J. Clin. Invest. 63: 536-539.

19. Shirai, T., and R. C. Mellors. 1971. Natural thymic cytotoxic autoantibody and reactive antigen in New Zealand Black and other mice. Proc. Natl. Acad. Sci. U. S. A. 63: 1412-1415.

20. Klassen, L. W., R. S. Krakauer, and A. D. Steinberg. 1977. Selective loss of suppressor cell function in New Zealand mice induced by NTA. J. Immunol. 119: 830-837.

21. Shirai, T., K. Hayakawa, K. Okumura, and T. Tada. 1978. Differential cytotoxic effect of natural thymocytotoxic autoantibody of NZB mice on functional subsets of T cells. J. Immunol. 120: 1924-1929.

22. Sakane, T., A. D. Steinberg, J. P. Reeves, and I. Green. 1979. Studies of immune functions of patients with sys- temic lupus erythematosus. T-cell subsets and antibodies to T-cell subsets. J. Clin. Invest. 64: 1260-1269.

23. Sakane, T., and I. Green. 1978. Protein A from Staphylococcus aureus - a mitogen for human $\mathrm{T}$ lymphocytes and $\mathrm{B}$ lymphocytes but not L lymphocytes. J. Immunol. 120: 302-311.

24. Perlmann, P., H. Perlmann, and H. Wigzell. 1972. Lymphocyte mediated cytotoxicity in vitro. Induction and inhibition by humoral antibody and nature of effector cells. Transplant. Rev. 13: 91-114.

25. Kumagai, S., H. Kotani, T. Sakurami, T. Tsunematsu, and H. Imura. 1978. PHA-induced and antibody dependent cell-mediated cytotoxicity in patients with various collagen diseases. Jpn. Arch. Intern. Med. 25: 309-318.

26. MacLennan, I. C. M., and G. Loewi. 1968. Effect of specific antibody to target cells on their specific and nonspecific interactions with lymphocytes. Nature (Lond.). 219: 1069-1070.

27. Wählin, B., H. Perlmann, and P. Perlmann. 1976. Analysis by a plaque assay of IgG- or IgM-dependent cytolytic lymphocytes in human blood. J. Exp. Med. 144: 1375-1380.

28. Fuson, E. W., and E. W. Lamon. 1977. IgM-induced cellmediated cytotoxicity with antibody and effector cells of human origin. J. Immunol. 118: 1907-1909.

29. MacLennan, I. C. M. 1972. Competition for receptors for immunoglobulin on cytotoxic lymphocytes. Clin. Exp. Immunol. 10: 275-283.

30. Hallberg, T. 1974. Inhibition of cytotoxicity of nonimmune human lymphocytes for sensitized chicken erythrocytes by aggregated human IgG. Scand.J. Immunol. 3: 117-125.

31. Williams, R. C., and A. D. Bankhurst. 1978. Clinical immunologic studies in systemic lupus erythematosus. Arthritis Rheum. 21: 5202-5209.

32. Scheinberg, M. A., and E. S. Cathcart. 1974. B cell and T cell lymphopenia in systemic lupus erythematosus. Cell. Immunol. 12: 309-314.

33. Wernet, P., and H. G. Kunkel. 1973. Antibodies to a specific surface antigen of T-cells in human sera inhibiting mixed leucocyte culture reactions. J. Exp. Med. 138: 1021-1026.

34. Zvaifler, N. J., and H. G. Bluestein. 1979. Antibodymediated suppression of antibody-dependent cytotoxic effector cell function. Clin. Immunol. Immunopathol. 13: 277-286.

35. Saal, J. G., E. P. Rieber, M. Hadam, and G. Riethmuller. 1977. Lymphocytes with T-cell markers cooperate with IgG antibodies in the lysis of human tumor cells. Nature (Lond.). 265: 158-160.

36. Handwerger, B. S., N. E. Kay, and S. D. Douglas. 1978. Lymphocyte-mediated antibody-dependent cytolysis: role in immune hemolysis. Vox Sang. 34: 276-280.

37. Jondal, M., and P. Gunven. 1977. Antibody-dependent cellular cytotoxicity (ADCC) against Epstein-Barr virusdetermined antigens. III. Reactivity in sera from patients with Burkitt's lymphoma in relation to tumor development. Clin. Exp. Immunol. 29: 11-15.

38. Kohl, S., S. E. Starr, J. M. Oleske, S. L. Shore, R. B. Ashman, and A. J. Nahmias. 1977. Human monocytemacrophage-mediated antibody-dependent cytotoxicity to Herpes simplex virus-infected cells. J. Immunol. 118: 729-735.

39. Scott, R., M. O. DeLandazuri, P. S. Gardner, and J. J. T. Owen. 1977. Human antibody-dependent cell-mediated cytotoxicity against target cells infected with respiratory syncytial virus. Clin. Exp. Immunol. 28: 19-26.

40. Quismorio, F. P., G. J. Friou, J. Schneider, M. Hutchinson, and B. Harding. 1976. In vitro activity of anti-DNA antibodies from SLE patients in antibody-dependent cell- 
mediated cytotoxicity. Int. Arch. Allergy Appl. Immunol. 52: 42-47.

41. Gershwin, M. E., W. Glinski, T. Chused, and A. D. Steinberg. 1977. Lymphocyte-dependent antibody-mediated cytolysis of DNA-anti-DNA coated target cells using human and murine effector population. Clin Immunol. Immunopathol. 8: 280-291.

42. Glinski, W., M. E. Gershwin, and A. D. Steinberg. 1976. Fractionation of cells on a discontinuous Ficoll gradient: study of subpopulations of human $T$ cells using anti-T-cell antibodies from patients with systemic lupus erythematosus. J. Clin. Invest. 57: 604-614.

43. Longmire, R. L., R. Mcmillan, and S. Ryan. 1978. Antibodydependent lymphocytotoxicity induced by immunoglobulin G from Hodgkin's disease splenic lymphocytes. Science (Wash. D. C.). 199: 71-72.

44. Diaz-Jouanen, E., A. D. Bankhurst, R. P. Messner, and
R. C. Williams, Jr. 1976. Serum and synovial fluid inhibitors of antibody-mediated lymphocytotoxicity in rheumatoid arthritis and systemic lupus erythematosus. Arthritis Rheum. 19: 142-149.

45. Feldmann, J-L., M. J. Becker, H. Moutsopoulos, K. Fye, M. Blackman, W. V. Epstein, and N. Talal. 1976. Antibodydependent cell-mediated cytotoxicity in selected autoimmune diseases. J. Clin. Invest. 58: 173-179.

46. Scheinberg, W. A., and E. S. Cathcart. 1976. Antibodydependent direct cytotoxicity of human lymphocytes. I. Studies on peripheral blood lymphocytes and sera of patients with systemic lupus erythematosus. Clin. Exp. Immunol. 24: 317-322.

47. Kumagai, S. 1979. Detection of immune complexes (IC) in sera of patients with SLE using inhibition of antibody dependent cell-mediated cytotoxicity (ADCC). Jpn. J. Allergol. 28: 7-14. 